Article

\title{
Integration of Multi-Criteria Decision Support with Infrastructure of Smart Services for Sustainable Multi-Modal Transportation of Freights
}

\author{
Dalè Dzemydienè ${ }^{1,2, *}$, Aurelija Burinskienè ${ }^{1, *}$ and Arūnas Miliauskas ${ }^{1,2}$ \\ 1 Department of Business Technologies and Entrepreneurship, Faculty of Business Management, \\ Vilnius Gediminas Technical University, Saulètekio av. 11, LT-10223 Vilnius, Lithuania; \\ arunas.miliauskas@vilniustech.lt \\ 2 Institute of Data Science and Digital Technologies, Faculty of Mathematics and Informatics, \\ Vilnius University, Akademijos str. 4, LT-08412 Vilnius, Lithuania \\ * Correspondence: dale.dzemydiene@vilniustech.lt (D.D.); aurelija.burinskiene@vilniustech.lt (A.B.); \\ Tel.: +370-68563352 (D.D.)
}

Citation: Dzemydienè, D.;

Burinskienè, A.; Miliauskas, A.

Integration of Multi-Criteria Decision Support with Infrastructure of Smart Services for Sustainable Multi-Modal Transportation of Freights. Sustainability 2021, 13, 4675. https:// doi.org/10.3390/su13094675

Academic Editor: Itzhak Benenson

Received: 19 March 2021

Accepted: 20 April 2021

Published: 22 April 2021

Publisher's Note: MDPI stays neutral with regard to jurisdictional claims in published maps and institutional affiliations.

Copyright: ( $\odot 2021$ by the authors Licensee MDPI, Basel, Switzerland. This article is an open access article distributed under the terms and conditions of the Creative Commons Attribution (CC BY) license (https:// creativecommons.org/licenses/by/ $4.0 /)$.

\begin{abstract}
The problems of developing online decision support systems concern the complexity of the transportation management processes, the multi-dimensionality of data warehouses (DWs), and the multi-criteria of decision making. Such issues arise in the management processes by supporting them with adaptable information and communication infrastructure for the management of the freight's transportation processes. Our research domain involves the assurance of infrastructure for the provision of smart services for the operative management of multi-modal transportation of freights under the conditions of the heterogeneity of communication channels and multi-criteria decision support. The complexity of managing multi-modal transportation processes raises some problems for ensuring the infrastructure for finding more optimal management solutions by the requirements of green development. This research aims to develop the approach for providing the infrastructure of intelligent smart services for adaptable implementation in management processes of online multi-modal freight transportation. The objectives are forwarded to construct the multicriteria decision-making components and integrate them into the multi-layered, computer-based information management of intelligent systems. We present the steps of extension of the structure of the knowledge-based system with a multi-criteria decision support method, and the possibilities to work under the conditions of wireless networks and the recognition of context-aware situations. The results are demonstrated for the analysis of alternatives by assessing the multi-modal transportation corridors between the East and West regions of Europe, and the opportunities to evaluate them for more effective managerial perspectives under sustainable development requirements.
\end{abstract}

Keywords: decision support system (DSS); multi-criteria decision making; multi-modal transportation of freights; smart services; information infrastructure; sustainable management

\section{Introduction}

Our research area concerns the digital transformations in the cargo transportation sector that influence new information and communication technology (ICT). Transport became one of the most important industries that are affected by important changes in the ICT sector. Changes are needed for the development of new kinds of infrastructure that are useful for managing such complex processes. The management of such processes is forwarded for supporting activities, which participate in all transportation chain cycles by achieving the sustainable development requirements and following the Sustainable Development Agenda's main goals [1].

New kinds of management means are analyzed in this paper by paying more attention to the implementation of the recent ICT and assessing the changes in intelligent transport 
development. The Action plan activities, provided by the Sustainable Development Agenda of the United Nations (UN), inspire more effective changes until 2030 [1]. The requirements of the sustainable development of transportation means inspire the management by "green" requirements and call us to reduce the transport pollution, particularly in densely populated areas, by shifting congestion from the road-to-road transport modes to increase the integration of other modes of transport in the common logistics transport chains. For these reasons, our research object became the multi-modal transportation structures with an adaptable smart service provision system that helps in the decision-making processes.

More attention nowadays is on paying for the identification of main engines, which affects the importance of digital transformations in transportation. By following the works of $[2,3]$, we would like to mention:

- New kinds of global digital transformation trends, which influence the development of infrastructure for new kinds of autonomous transportation;

- Continuous digital technology advantages, which are pushing the organizational changes in transportation management and their business models;

- Changing management priorities by implementing ICT for the transportation processes of goods and integrating new kinds of smart services, which can be provided in the online mode for all transportation processes.

Such services are specially developed and based on wireless communication and monitoring possibilities by implementing technologies such as GPS, GPRS, 4G or 5G wireless mobile protocols, and artificial intelligence systems with integrated functionalities of Geographical Information Systems (GIS) for the management of transport means. However, the need for the development of smart decision support systems is still very actual. By influencing novel ICT, the competition in transportation is changing dramatically. Companies are increasingly competing globally with digital possibilities; they become most valuable by pushing oil and natural gas producers from leading positions. Its size no longer characterizes a competitive advantage, and the priority became the speed of responding to technology changes [4].

Our research objectives are forwarded for developing the online multi-criteria decision support system (MC-DSS) with possibilities of helping in management processes of multimodal transportation of freights. We are presenting the requirements for infrastructure development of the MC-DSS functioning. Such infrastructure is based on different kinds of wireless communication possibilities, which became heterogeneous in the wide spectrum of implementing communication channels, the network of sensors, GIS, and monitoring support structures. The problems arise in developing operatively working systems by providing the solutions for more effective cargo transportation management procedures.

Some issues arose when we would attempt to apply the technological platform of the internet of things (IoT), which is applied not only to the infrastructure of stationary objects but also to moving (transport) objects [5]. The infrastructure of IoT for managing of moving objects became very dynamic.

As mentioned in the limitations of our research, we will restrict our consideration to only some types of freight transportation processes, which are based on land conditions, and we will try to analyze the common structures of the interactions between trucks, railway transport, and sea/water vehicles. We did not include types of air transportation in this paper.

Another investment is the innovations of the development of computer-based artificial agents, which can provide online decision support in the crucial stages of management by helping in the complex multi-modal transportation processes of choosing transportation corridors by land, based on different cargo kinds, and excluding drivers from these paperconsuming jobs, replacing them with automated, computer-based smart service procedures.

Our forwarded research aim is to develop the multi-criteria decision support system (MC-DSS) working in wireless communication infrastructure, and present an approach to implement the methods of working mechanisms of the intelligent agents. The results are demonstrated by describing the main components of the MC-DSS architecture, and 
by representing the constructional methodology of integrating such parts in the whole system with other smart services. The MC-DSS system under development has had some important requirements. One of them is an ability to work online and to assess the importance and priority of alternative multi-modal transportation corridors by analyzing two directions from West to East Europe. The results are demonstrated by choosing the methods for constructing the MC-DSS for multi-modal and inter-modal transportation processes. As a part of the smart service provision system, the MC-DSS will have the possibility to help in the determination of priorities by choosing the best route under real conditions of context-aware information, by evaluating the different alternatives provided for the assessment of multi-modal corridors for cargo transportation.

For the construction of the knowledge base system (KBS) for the MC-DSS, the design of the real working conceptual models of the application domain, which became a background of the computer-based ontology, is important. This ontology is used for designing metamodels of the repositories of working data-warehouses (DWs), which are applied for the construction of the smart services and their scenarios. We chose the Unified Modelling Language (UML) for designing the knowledge base conceptual models. Another part of the knowledge base (KB) represents mechanisms and algorithms for more deepened reasoning, which are described by various decision-making models and methods, such as the rules of decision-making, the recognition of priorities of criteria for evaluation of alternatives, and the relations of goals with planning results. The artificial planner is constructed as an artificial agent with the implementation of multi-criteria decision methods. One of them, as the construction of linguistics comparison sets, is described for the illustration of such part of the KBS construction. These sets are used for the linguistic description of the assessment process and can be related to the fuzzy logic approach, which we are planning to integrate into the artificial planner for the description of the choosing processes of the multi-modal transportation corridors. The construction of decision matrixes is applied to the finding of more optimal plans for transportation trips. The integration of the mentioned methods is described in our research methodology.

The paper's structure is provided as follows: related works are analyzed in Section 2 by paying more attention to the assessment of the multi-dimensional decision support methods. The methodology of experimental and empirical research is provided in Section 3. The implications of the knowledge base constructions that describe many aspects of the road's infrastructure topology, vehicular communication networks, and the MC-DSS system's architecture are described in Section 4 . The case study analysis and the results are presented in Section 5, by implementing the methodology and the MC-DSS constructions. The results show system functionality of choosing the cargo transportation possibilities by evaluating the appropriate multi-modal corridors from West to East Europe directions. The discussion, limitations, plans, and conclusions are presented at the end of the paper.

\section{Related Works}

The problems with our research are linked with the sustainable management of cargo transportation processes. They are evident for the analysis of complexity and dynamicity of such phenomenon by the requirements of Sustainable development goals (SDG) for transportation, which are declared by the UN in the Sustainable Development Agenda (SDA) until 2030 [1].

In the area of land freight transport, intelligent transport systems (also known as road telematics) have been under development for the last 20 years. Some programs are now widespread and well known. The transport and storage sector is facing daily growth in the use of new smart services. Cargo vehicles generate a wide variety of data, from the driver's driving readings to cargo vehicle technical information. Digital information generated by freight vehicles, which is systematically presented to the end driver, is slowly becoming the future of this business. The main functions of intelligent services are traffic information, freight vehicle information, environmental information and driver behaviour information, as well as messages, situation alerts, and decision making. For example, 
several million freight vehicles have built-in navigation systems that can handle real-time traffic and travel information.

The types of communications allow users to provide road safety services by sharing safety information to avoid accidents, accident investigation afterwards, or to avoid traffic congestion. Other groups of services are the types of services for specialists of logistics, which are related to distribution and storage processes. To handle real-time decisions, it is necessary to exchange the available data with terminals and warehouses, which could also minimize the operational time connected to the freight vehicle's waiting time in front of these premises. Many researchers focus on improving the efficiency of communication between freight vehicles, but specific aspects of such problems as network disconnections, quality of service (QoS) metrics, traffic safety, scalability, and the communication features between vehicle and warehouses remain especially important and unsolved in reality.

We chose research works for analyses that are useful from the perspective of ICT development for transport management processes, and such multi-criteria, decision-making methods, which are applicable for the development of smart service systems in this sector.

\subsection{Review of ICT Development Initiatives for the Transport Sector}

The assessment process includes the requirements and possibilities for providing multi-componential and smart services for transportation processes by incorporating them into the multi-layered structure of required data and information systems (IS). Some important components of such infrastructure are described in our previous works [6-8]. The methods enable the evaluation of decision support and can be revealed in more appropriate ones for supporting the functionality of new kinds of complex transportation processes and services.

Together, the Digital Europe priorities enter into developing new kinds of ICT with the development of new kinds of smart services, mentioned by the highest level of political priorities in conjunction with the European Green Deal [9]. European Strategy Papers, which plans are concerning the activities until 2030, are provided with the requirements for responding authorities to pay more attention to global trends of ICT development [10]. The countries of Europe recognize the importance of the data economy. Modern oil, i.e., data, will help society and business reap the greatest dividends from the digital transformation. Companies need to learn to employ data and create the added value in management with ICT. For their part, the public sector has helped them in creating a legal and technological environment for a secure data exchange in various directions (in infrastructure, for the development of services by providing concrete platforms for realization of models, such as Government to Business (G2B), Business to Business (B2B) and Business to Governance $(B 2 G))$, and data exchange triangles. Innovative platforms are created based on secure and ethical state-of-the-art technology. They are based on methods and equipment of artificial intelligence, the Internet of Things (IoT), block-chain circuits, and other applications [4,5].

The most promising digitization technologies help in achieving the goals of sustainable development of transportation. More attention is paid to the multi-modal transportation effectuations by removing the freight transport burden from road transport and shifting it to the rail and sea (or air) modes of transport.

The new management systems' development process is based on artificial intelligence systems, supercomputers, cloud and peripheral computing, quantum technologies, and technologies to manage block-chains (circuits) [10]. The systems are created on such technology platforms, including virtual and augmented reality, communication protocols based on the 5G connectivity, and robotics. All these innovative means are helpful in the realization of the potential of data of intelligent transportation processes. In developing these new kinds of support, some components are important for the creation of new applications by providing special artificial methods that concern the technologies of the Internet of Things (IoT), working on wireless networks $[4,9,10]$.

The assessment of supporting infrastructure for the delivery of e-services is revised in the second layer of the presented methodology. It follows the evaluation of the structure 
of meta-models of information systems (ISs) and technologies of cloud computing by maintaining big data stores as data warehouses (DWs), and computer-based flows of e-documents for supporting the managerial and administrative processes during the cycles of transportation [7].

We have limited our consideration of analyzing multi-component landscape modes of transportation of freights (i.e., goods, cargo) by developing adaptable decision support tools integrated into the overall smart service delivery system.

\subsection{Review of Multi-Criteria Decision Support Methods Used for the Transportation Research Area}

For a long time, authors apply multi-criteria decision making and decision support (MCDM) methods by solving transport problems. Various decision-making problems are encountered in multiple situations, where many alternatives and actions are needed for selection. The procedures of decision making follow the choices, which are based on the sets of attributes and reveal their importance. Depending on the set of individual options that some characteristics can describe, three different types of analyses can be performed:

- To ensure that decision-makers follow the "rational" behaviour-by the implementation of statements of some utility theory, value functions, and evaluation of distances from the proposed solution to the ideal point;

- To give advice that is based on reasonable (undisputed) rules;

- To find the desired solution that is more important in comparison to the partial solution hypothesis.

Multi-criteria assessment methods are used in finding out the alternative that has received the highest score (Table 1). Numerous methods were developed for the analysis of many traits. Multiple attribute analysis is a useful tool for solving many economic, management, and other problems. Widely known methods are used for the acceptance of numerous attributes. We can mention such methods as Complex Proportional Assessment of Alternatives (COPRAS) [11], Technique for Ordering of Preference Systems by analogy to Ideal Solution (TOPSIS), Vise Criterion Optimization and Compromise Solution (VIKOR), Analytic Hierarchy Process (AHP), and others. Some development reviews and implementation by authors of these methods in the transport research area is described in Table 1.

One of the most important, and most often applied, is COPRAS [11] multi-criteria assessment method that assumes a direct and proportional dependence and adequately describes each criterion's alternatives, values, and weight. In the COPRAS with grey relations (COPRAS-G) model [12], the alternatives' parameters are determined by the degree of grey ratio and are expressed in intervals. The COPRAS method is generally considered an accurate one. Given that transport and logistics decisions involve evaluating various criteria with opposite values and possible solutions, the COPRAS method is the most useful for such considerations.

TOPSIS and VIKOR are more sophisticated methods, sensitive to baseline data changes and difficult to proportionate assessment; they differ in the criteria used and the technique for normalizing the original data. TOPSIS is used to analyze the proximity to the ideal point (the alternative with the shortest Euclidean distance to the perfect variant is chosen). TOPSIS uses a non-standard, so-called vector normalization. VIKOR also uses a specific type of normalization.

There are also other MCDM methods. A higher rating defines a partial rating for a set of alternatives, including integer programming techniques to solve the optimization problem. In uncertainty, fuzzy COPRAS, fuzzy TOPSIS, COPRAS-G [12], or game theory methods may be used.

By applying these MCDM methods, the authors solve various problems in transport. The authors have presented the concrete MCDM methods for selecting a sustainable transport plan based on the sustainability index [13]. In the study, the authors used the 
weighted amount model. The authors presented a new methodology of assigning of weighting factors related with transport sustainability criteria in the projects [14].

To address the problem of inaccuracy and subjectivity, the authors applied MCDM models in blurred environments. Given that the traffic system is the life of every country framework for economic development, the authors of [15] proposed that the AHP approach should be applied in selecting the best project implementation of urban traffic projects. The model was tested in a real-life system and gave reliable results. There are major shortcomings in applying of the AHP model, so the validation of the obtained results is more difficult to perform, as discussed in [15]. The modified AHP method, with additive fuzzy transitivity relationships for solving these problems, is presented in [16]. The model was tested when selecting a contractor for the construction of the transport infrastructure. One solution is made for the improvement of the sustainability of transport usage, i.e., a variety of alternative usage of fuels and vehicle propulsion are provided in such a system. In this situation, we can evaluate the specific vehicle characteristics by using the sustainability index, described in [17].

Required indicators were identified and divided into five categories: environment, technology, energy, economy, and consumer socialization by concerning sustainability requirements. Then indicators are generalized by using the weighted sum method (WSM). Moreover, by following [18], the selection of the vehicle propulsion for fuels is based on three key aspects of sustainability. As recommended in the PROMETHEE method, the performance of the assessment of criteria, and alternatives by using the preference ranking organization method, are organized.

Intermodal transportation can greatly improve the sustainability of the transportation system. It is necessary to choose the terminals' optimal location about the different transport requirements of various participants' process. To achieve these objectives, new hybrid MCDM models are proposed for the site selections [11,19].

Sustainable transport systems have become a necessity in modern life, especially in safeguarding large cities due to various harmful effects on the environment. The methods for selecting the best alternative for implementing it into the transport systems according to 24 criteria are divided into three categories [20]. The above process consists of three steps, and the TOPSIS method is applied in conjunction with the fuzzy theory for evaluating the criteria and choosing the optimal alternative. The results of [21] offer an evaluative and logical approach for the development of sustainable transport indicators in selecting smaller sets of indicators for the sustainable transport system by using the AHP and SAW (i.e., Simple Additive Weighting) methods. Although the transport planning methods have been improved in the past several years, according to the results in [22], which enhance some aspects of sustainability in transportation, it is necessary to apply a multi-layered approach, based on different possibilities of artificial intelligence methods, GIS services, and others.

Moreover, it is essential to integrate the multi-criteria decision-making method's proposed approach. Assessing the transport system's sustainability in an individual European country, economic, ecological, and social indicator was presented in [23]. The method followed the elimination and the choice of expressing reality (ELECTRE) was used to modify the system and was based on the absolute value threshold. A system for selecting sustainable transport projects in urban areas in developing countries was offered by [24]. The choice of alternatives is based on localized sustainability by using the score index and implementing the AHP method. In addition to the AHP method, assessing the sustainability of different transport solutions, such as transport mode, must be implemented. For example, the research of [25] proposes the BWM (Best Worst Method) and COPRAS for the selection of the proper road for vehicles [26]. 
Table 1. Review of applications of different MCDM in the transportation research field.

\begin{tabular}{|c|c|c|}
\hline The Application Areas of MCDM in the Transport Field & MCDM Method & Authors of Such Investigations \\
\hline Estimation of road design & COPRAS & [11] \\
\hline Comparison of container terminal technologies & COPRAS-G & [12] \\
\hline Locating forest roads & AHP and COPRAS-G & [27] \\
\hline Selection of road transport for transportation & BWM-COPRAS & [26] \\
\hline Risk assessment for critical infrastructure case & Fuzzy COPRAS & [28] \\
\hline Evaluation of railway operation safety & TOPSIS & [29] \\
\hline Evaluation of quality for rail transit system service & Fuzzy TOPSIS & [30] \\
\hline Determination of end-of-life vehicles in reverse flow case & DEA TOPSIS & [31] \\
\hline Determination of the position of air traffic control radar & Hybridized TOPSIS & [32] \\
\hline Selection of transport sharing station & WASPAS and TOPSIS & [33] \\
\hline Ranking bridge design alternatives & TOPSIS FADR & [34] \\
\hline Solving transport problems & $\begin{array}{l}\text { ARAS, COPRAS, MOORA, } \\
\text { VIKOR, TOPSIS, WASPAS }\end{array}$ & {$[35]$} \\
\hline
\end{tabular}

Numerous studies have examined the best way to choose the appropriate methods for adaptable decision-making in transportation management processes by determining the system of different criteria and their importance for supporting the best solution under the recognition of real situations.

\subsection{Review of Usage of Criteria in the Models of Decision Making for the Choice of the Alternatives} in the Multi-Modal Freight Transportation

The review of using different criteria in decision-making models is presented in Table 2 to represent some ideas of the choices of the best alternatives in managing multi-modal freight transportation. Establishing the concrete criteria for accidents in different research works is a complex procedure.

The results of the analysis show that most of the multi-criteria application methods are applied for physical transport questions and the evaluation of transportation services. However, only several authors apply MCDM to the revision of online solutions.

The ideal security in the multi-modality of transportation processes and their management depends on many kinds of transporting and shipping factors. There are many laws, agreements, and practices to achieve security measures and to implement the means for ensuring security.

At the final stage of our review, we can conclude the importance of applying methods for developing reasoning models and applying them to our MC-DSS under construction. We involve the approval of the MCDM results, which are obtained as:

- The results of the comparison with other multi-criteria (MCDM) models are presented and have a ratio for future implementation;

- It is important to implement the stability analysis of the results in a dynamic environment of transportation;

- It is important to develop the methods for stability analysis to implement them in obtaining the results when the weights of the criteria are changed. 
Table 2. Results of the review of criteria implementation in the models of decision support for multi-modal transportation of freights.

\begin{tabular}{|c|c|c|c|}
\hline No & Name of Criteria & MCDM Method & Authors \\
\hline 1 & Transportation cost & IT2FSs & [36] \\
\hline 2 & Duration of transportation & ELECTRE and AHP & [37] \\
\hline 3 & Reliability of corridor & ELECTRE and AHP & [38] \\
\hline 4 & Transportation safety and security & Fuzzy TOPSIS, ELECTRE and AHP & {$[38,39]$} \\
\hline 5 & Quality of transport system elements & Fuzzy TOPSIS & [39] \\
\hline 6 & Customs process efficiency & Fuzzy AHP & [40] \\
\hline 7 & Level of transportation competitiveness & ELECTRE & {$[41]$} \\
\hline 8 & Performance of mode-based service & EATWOS & [42] \\
\hline 9 & Capacity of transportation mean & IT2FSs & [36] \\
\hline 10 & Energy consumption (Environmental friendliness) & ELECTRE and AHP & {$[38]$} \\
\hline 11 & Infrastructure resilience (ecological stability) & DEA & [43] \\
\hline 12 & Number of possible mode assessments & DEA & [43] \\
\hline 13 & Availability of communication network & AHP and TOPSIS & [44] \\
\hline 14 & Number of occupational accidents & Fuzzy AHP & [45] \\
\hline 15 & Transport of hazardous goods & LNN WASPAS & [46] \\
\hline 16 & 3PL transportation provider evaluation & GM, Fuzzy TOPSIS, Fuzzy AHP & [47] \\
\hline 17 & GIS, geometric data of infrastructure characteristics & Fuzzy OWA & [48] \\
\hline
\end{tabular}

Herein: IT2FS-Interval type-2 fuzzy sets; EATWOS-Method consists of an entropy and efficiency analysis technique with output satisfaction; LNN—Linguistic Neutrosophic Numbers; 3PL—third-party logistics provider; GM—geometric mean; GIS—Geographic information system; OWA-Ordered Weighted Averaging.

\section{The Methodology of Research for Provision of Smart Services for Sustainable Management of Multi-Modal Transportation of Freights}

The objective for developing the online MC-DSS is to provide the computer-based structures of supporting all required information systems, databases (DBs), and data warehouses (DWs), including the communication channels' needs based on wireless technology. The multi-modal transportation of freights is analyzed at the first stage of developing adaptable and online MC-DSS. The complexity of processes is recognized and formally described by the conceptual models by implementing computer-based ontology tools.

The decomposition of the influencing components is applied by implementing some construction tools of computer-based ontology. The multi-modal transportation infrastructure is considered as dynamically changing and complex (Table 3). Decisions are based on many different factors, such as:

- The assessment of the technical infrastructure of transportation and informational infrastructure, which is provided for services needs in the multi-modal transportation processes;

- The assessment of organizational priorities and dynamic managerial aspects;

- The comparison of the real situation of transportation processes and reports, with the preparation of effective and adaptable planning of actions;

- The evaluation of risks and the recognition of risky situations, which are in-line decision making seeking to apply corrective actions. 


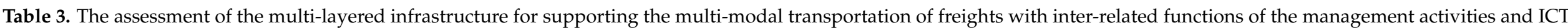

\begin{tabular}{|c|c|c|c|c|}
\hline Layers of Infrastructure & $\begin{array}{l}\text { Components of Transportation } \\
\text { thought the Parts of Infrastructure } \\
\text { and Decision Support Sub-Systems }\end{array}$ & $\begin{array}{l}\text { Detailing Components of } \\
\text { Sub-Systems }\end{array}$ & Kinds of Applying ICT & $\begin{array}{l}\text { Management Activities for Organization } \\
\text { of Associated Processes for Multi-Modal } \\
\text { Transportation of Freights }\end{array}$ \\
\hline $\begin{array}{l}\text { I Layer of backgrounding of } \\
\text { transportation networks }\end{array}$ & $\begin{array}{l}\text { The physical-technical systems (PTSTs) } \\
\text { for multi-modal transportation of } \\
\text { freights }\end{array}$ & $\begin{array}{ll}\text { - } & \text { Networks of roads of automobile } \\
\text { transport mean; } \\
\text { - Sea routes; } \\
\text { - Networks of roads by rivers and } \\
\text { - } \quad \text { lakes; } \\
\quad \text { Networks of railways. }\end{array}$ & $\begin{array}{ll}\text { - } & \text { Technique and types of equipment of } \\
& \text { road networks; } \\
\text { - } & \text { Wireless communication networks; } \\
\text { - } & \text { Wireless Sensor Networks (WSNs); } \\
\text { - } & \text { Olobal positioning systems (GPS); } \\
& \text { Systems (GIS); } \\
\text { - The infrastructure of roadside units } \\
\text { (RSU); } \\
\text { - Systems of smart service provision; } \\
\text { - Interconnection of information systems } \\
\quad \text { with cloud-computing services. }\end{array}$ & $\begin{array}{l}\text { - The management of the infrastructure } \\
\text { of transportation networks and } \\
\text { situation evaluation before decision } \\
\text { making; } \\
\text { - Planning of activities for PTSTs } \\
\text { changes; } \\
\text { - Monitoring of activities; } \\
\text { - Supporting the quality of the road's } \\
\text { networks; } \\
\text { Decision making for maintaining green } \\
\text { transportation corridors; } \\
\text { - } \quad \text { Asaluation of conditions of the air; } \\
\text { information including the prognosis of } \\
\text { weather conditions, evaluation of } \\
\text { freezing conditions of water bodies, } \\
\text { and other types of roads; and } \\
\text { information support for informing } \\
\text { about the real conditions of weather } \\
\text { changes. }\end{array}$ \\
\hline $\begin{array}{l}\text { II Layer of the infrastructure of } \\
\text { freights reloading in multi-modal } \\
\text { transportation processes }\end{array}$ & $\begin{array}{l}\text { The infrastructure of routes and } \\
\text { reloading terminals for supporting the } \\
\text { multi-modality of transportation }\end{array}$ & $\begin{array}{l}\text { ISs and monitoring data warehouses } \\
\text { (DWs), which provide information } \\
\text { about the works of terminals and } \\
\text { involved in these processes the } \\
\text { reloading of transportation units with } \\
\text { goods include: } \\
\text { - Terminals from automobiles } \\
\text { (auto tracks, etc.) to rail wagons; } \\
\text { Terminals from rail wagons to } \\
\text { water transport; } \\
\text { Terminals from automobiles } \\
\text { (auto tracks, etc.) to means of } \\
\text { water body transport. }\end{array}$ & $\begin{array}{l}\text { Equipment of terminals for monitoring } \\
\text { of reloading processes of transporting } \\
\text { units (trailers, containers) and other } \\
\text { objects; } \\
\text { Online geographical information } \\
\text { systems (GIS); } \\
\text { - The infrastructure of roadside units } \\
\text { (RSU); } \\
\text { - Systems of smart service provision; } \\
\text { Interconnection of information systems } \\
\text { with cloud-computing services. }\end{array}$ & \multirow{2}{*}{ 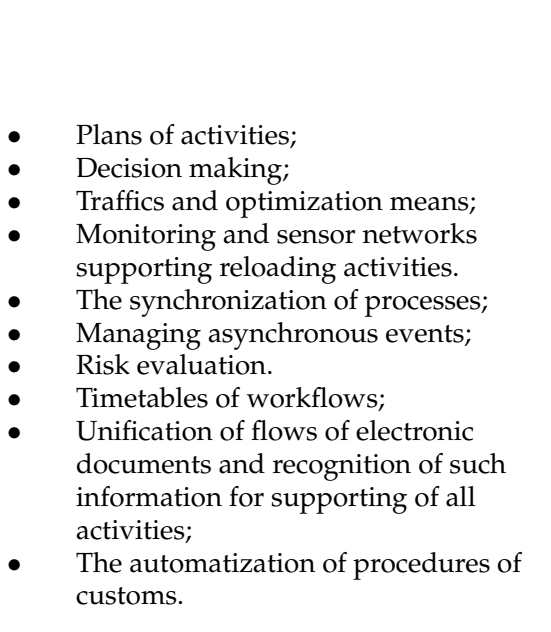 } \\
\hline $\begin{array}{l}\text { III Layer of supporting } \\
\text { transportation activities of the } \\
\text { junction-node (for example cross } \\
\text { boarding nodes, cities) }\end{array}$ & $\begin{array}{l}\text { The infrastructure of junction-nodes } \\
\text { for example, as cross boarding nodes, } \\
\text { cities of formation of transportation } \\
\text { corridors of multi-modal } \\
\text { transportation }\end{array}$ & $\begin{array}{l}\text { International cross boarding points } \\
\text { between related countries in analyzing } \\
\text { road network }\end{array}$ & $\begin{array}{l}\text { - Time-consuming processes and } \\
\text { optimization of procedures of customs } \\
\text { cross boarding, etc. }\end{array}$ & \\
\hline
\end{tabular}


Table 3. Cont.

\section{Layers of Infrastructure}

Layer of the infrastructure of enterprises (parks) of transport means, stories

The infrastructure of enterprises of transport means for supporting of parks, stories, and evaluation of the location of transport means Compt
Components of Transportation and Decision Support Sub-Systems Sub-Systems

- Systems for the organization of

different transport means;

- $\quad$ Systems for assessment of kinds and status of transport means

Management Activities for Organization

of Associated Processes for Multi-Modal Transportation of Freights

- Types of equipment for transport

- Technique

Protocols for computer-based communication networks based on wireless communication
- $\quad$ Supporting a high quality of work of transport parks and transport means;

- Transportation traffics;

- Supporting of drivers,

- Planning of works and activities by including all participating parties - Evaluation and management of risks. 
The cycles of multi-modality include important features of such factors as:

- The goods are transported by the same transport unit using several different modes of transport;

- The measuring and assessment of a long transmission cycle;

- The conditions of the international nature of the shipment;

- The complex connections between individual transport chains;

- The relationship between time and geographical dependences of transportation processes.

For evaluations and identification of many sub-systems, we need to ensure the structure of our complex mechanisms that interact as internal or external parts and provide the best solutions for optimizing management processes.

- $\quad$ The general information for multimedia services;

- The means for road safety and traffic monitoring services;

- The provision of management services;

- The ICT infrastructure for vehicle engine monitoring information and road conditions is monitoring and there are possibilities to analyze.

- The previously implemented works' patterns must be used according to the evaluation results in the real conditions of situations.

We reveal important requirements for experimental research. The structure of the representation of our domain has the multi-layered structure in the MC-DSS under development. The multi-modal transportation analysis can be divided into three types of transportation modes with a more detailing description of each interaction.

For the definition of the interactions between objects in transportation processes by analyzing the underground land conditions, the roads are specified as structures, including the main conditions of land-based networks, i.e.,:

- The roads networks for the automobile-motorized and/or autonomic transport means;

- The road networks for railways;

- The routes by water transport, including other water bodies (seas, rivers, lakes, transitional waters, etc.).

Such means diverse by a wide spectrum of heterogeneous wireless communication means. The layers of infrastructure have be recognized as interactions that are required to represent by some levels as well. Each layer reflects some closely interrelated functions of the activities (Table 3).

The cycles of multi-modality include important features of such factors as:

- The goods are transported by the same transport unit using several different modes of transport;

- The measuring and assessment of long transmission cycle;

- The conditions of the international nature of the shipment;

- The complex connections between individual transport chains;

- The relationship between time and geographical dependences of transportation processes.

An example of a conceptual structure for the description of highway network roads is presented in Figure under Section 4.1. How such networks are equipped with the necessary infrastructure of sensors and transportation process regulation techniques is another side of all infrastructure. We understand that such means diverse by a wide spectrum of heterogeneous wireless communication means. Such layers must be recognized as interactions that are required to represent by some levels as well. Each story reflects some closely interrelated functions of the activities (Table 3).

The physical-technical system of multi-modal transportation of freights consist of:

- Networks of roads of automobiles; sea routes, networks of roads by other water bodies, and railways;

- The infrastructure of terminals for the organization of reloading;

- Types and status of transport mean. 
The assessment and implementation of such components are needed for developing the real working MC-DSS. We are trying to integrate all of these components in the common infrastructure of smart services provision for more adaptable management of operative multi-modal transportation processes.

For the methodological description of the empirical research part, we would like to present a more detailed style (in Section 5) and describe the constructions of the adaptable MC-DSS. The characteristics of the goods recorded on the CARNET-TIR cards (i.e., the e-documents are issued according to the Transport International Router and recognition of data in TIR cards). Such e-cards have reflected the information about the specifics of the carried goods. As goods may be of different types, e.g., ecological hazards (which may be dangerous in an unforeseen accident), environmentally hazardous substances may be harmful to the environment; freights of non-standard dimensions; freights requiring particularly high reliability, etc.

Route selection requires specific information, which is particularly important in designing and developing intelligent service systems. Such data are recognized as contextual information and influence their importance on decision-making operations.

The road's technical conditions should allow determining the road surface's technical needs (or other characteristics) of the selected route for a specific period of seasons. These requirements can help to describe the technical conditions of the road. They may also affect the package of requirements for transporting goods during a certain period of the year and are connected to the meteorological conditions' prognosis.

At the next stage of system development, it is important to define how the required parameters will be entered (measured and calculated) and how reliable sources of expertise will determine these parameters' specific values.

\section{Knowledge Representation for the MC-DSS}

In this section, we would like to provide some examples of knowledge base models required for informational infrastructure support. Our consideration is restricted to the analysis of some aspects. We will not pay attention to analyzing the communication channels' technology because such analysis is out of our research consideration scope.

\subsection{The Conceptual Architecture of Decision Support Processes in the Finding of Adaptable Solutions}

The main purpose of the MC-DSS is a sustainable freight transportation planning and control process. The use of fixed offline plans is not suitable for such a dynamic environment. Therefore, modifications mentioned in research [46] or the re-planning at the possible points of trips might be needed. We are presenting some levels of planning and control of multi-modal transportation corridors in the MC-DSS (Figure 1):

- The operational planning level, in which the planning process of freight transportation is presented:

The field-level planning;

Control in which the processes are performing operatively and proceed during transportation processes.

- The existing situation is monitored and plans and discrepancies from the initial plan are identified.

Based on this, we are creating the conceptual architecture of the MS-DSS (Figure 1) based on the representation of components described as main in the 1 Layer of our proposing approach (Table 3) and represents the main processes of the trip's planning. The planning processes are performed using hierarchical planning. The architecture consists of two interacting components: operational management sub-system and information infrastructure of the field (application area) by describing it as an information support sub-system. 


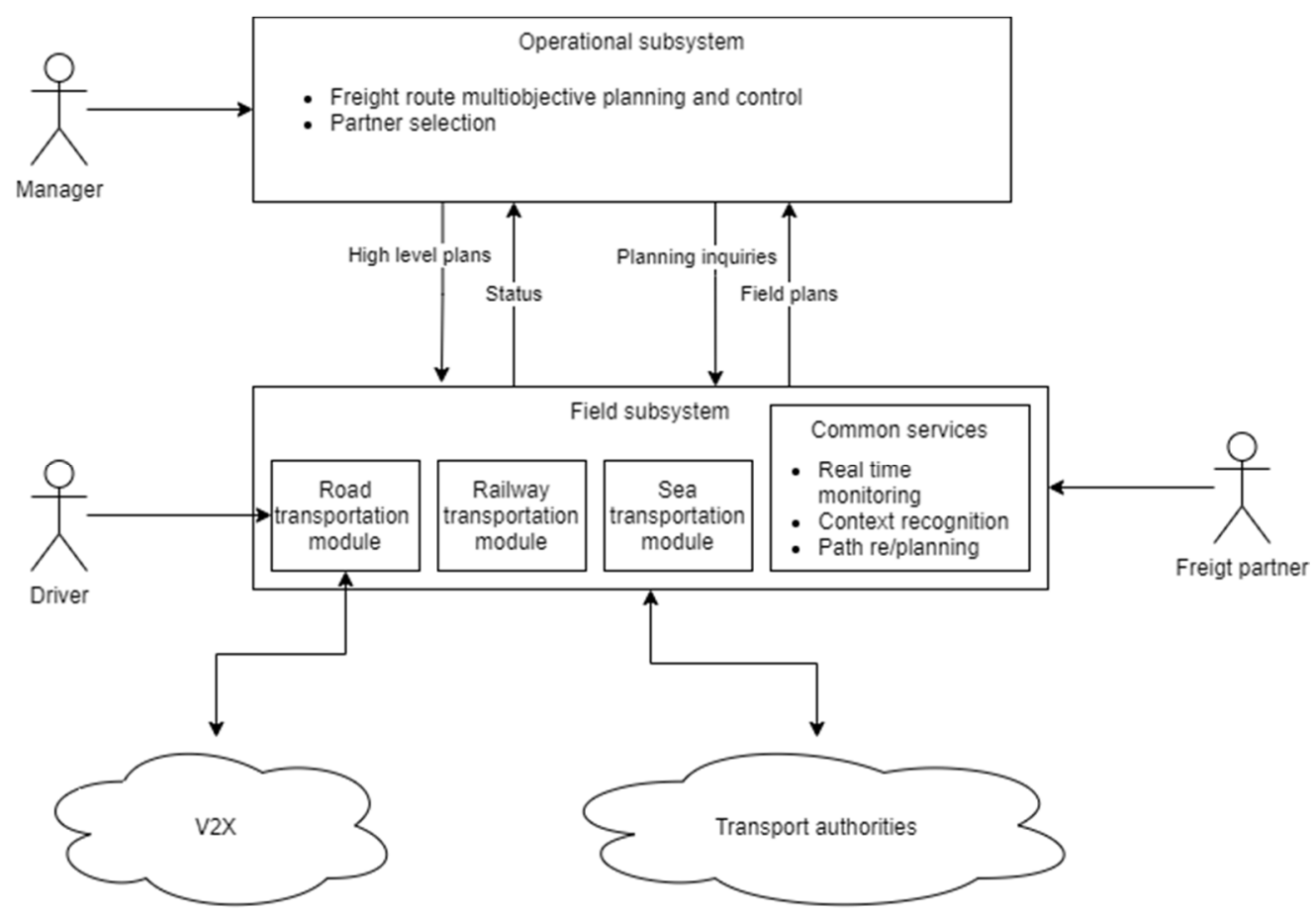

Figure 1. The conceptual architecture of the communication of main actors and activity components of the MS-DSS.

The decision support operational sub-system is focused on high-level planning and control. By high-level plan, we mean finding the optimal combination of transportation modes based on multiple objectives. Therefore, the proposed multi-objective genetic algorithm returns a set of non-dominated solutions that can be provided to the managers for the final choice. The result of operational planning is the single-level plan sent to the field module.

The field module focuses on transport mode-specific planning and efficient freight delivery control based on operational level plans. It also assists operational level planning by evaluating the most optimal transportation mode (chosen at the operational level). The main user of this sub-system depends on transport means. For road transportation, it is a driver. The road transportation module is connected to other road entities using V2X (vehicle to everything) communication. Higher-level operational plans constrain path planning and re-planning.

\subsection{Agent-Based Sub-System Architecture for Transportation Planning and Control Components}

The artificial agent-based approach is one of the popular ways for developing structures of smart service provision in complex and dynamic domains [47]. The artificial agent structure based on the Belief-Desire-Intention (BDI) working mechanism of the agent's activities is one of the practices for developing architecture of such software intelligence components. The deliberation loop enables an agent to select the most suitable plans from the provided situation's description. The agent is working by the algorithm that commits to achieve the selected goal with specified intentions. However, the reasoning loop gives the tools for a developer to create a new type of situation-aware agents. The agent constantly monitors and changes commitments when achieving the selected goal become irrelevant.

How such type of BDI agent architecture is applicable for the multi-modal transportation domain is represented in Figure 2. 


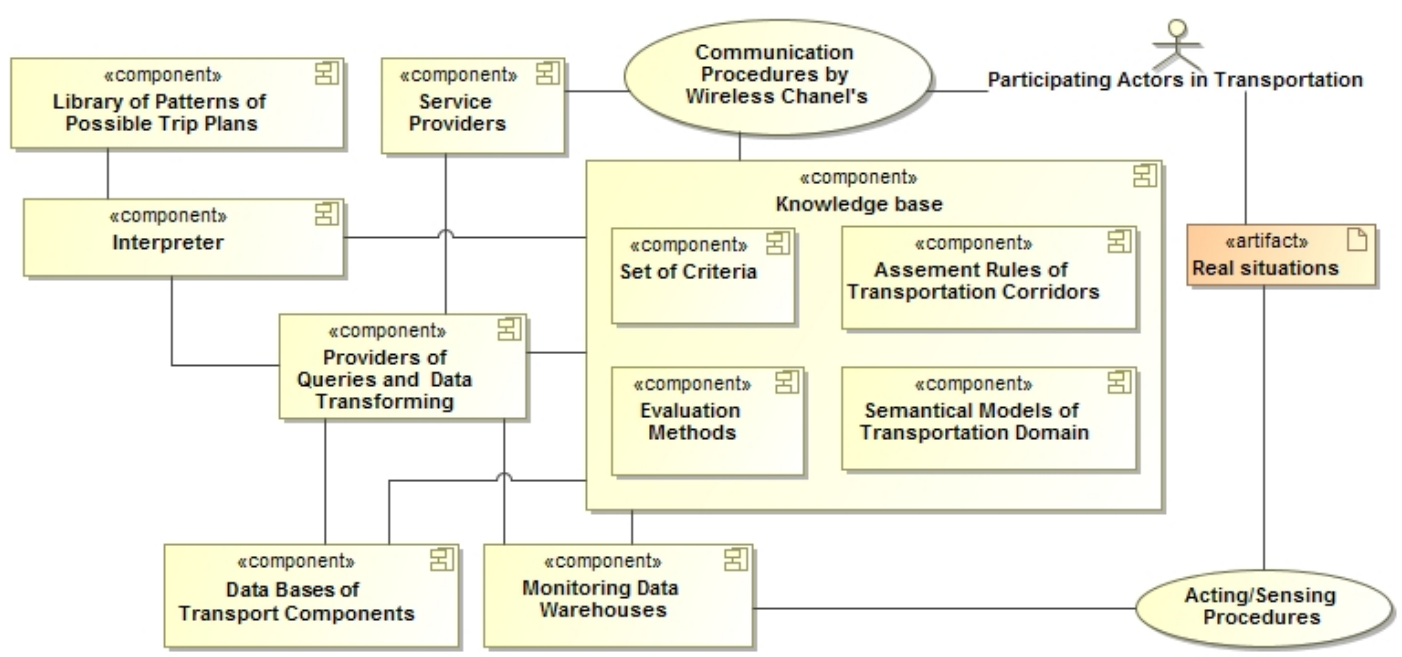

Figure 2. The architecture of the provision of smart services based on BDI agent working mechanisms.

The architecture of the BDI agent work implements some important concepts such as beliefs, desire, and intention. Beliefs are facts connected with the knowledge base (KB) and provided for the software component agent. The KB is constructed by some layers and provide a multi-component structure of knowledge about the transportation world (Figure 2). In our system, the KB include some components. Desires are specific states of the world agent that is seeking to achieve. In our system, the component as the Library of patterns of possible trip plans is designed as the library (i.e., data warehouse) and contains patterns of previously obtained plans. By selection of the needed plan pattern, the agent acts based on the goal direction and seeks to achieve the target states. Intention represents the possibilities to achieve the target state from the current state of the agent. The goals of the agent are committed to being achieved. The BDI agent working system's core is an Interpreter that implements the deliberation cycles and connects other parts of the system.

Interaction with the real environment/world (i.e., artifacts as Real Situations) is carried out by using the Communication Procedures and the Acting/Sensing modules. Acting/Sensing procedures are merged since the software agent interacts with the world, by using other web services based on the REST architectural style. The sensing can occur only by sending the request and receiving responses. The formal description of the BDI agent is provided by its working mechanisms and agent knowledge base implementation. The more formal description is represented using concepts and the Resource Description Framework (RDF) graph data model's abstract syntax. Each graph consists of triples, where each triple has the subject, object, and predicate. One part of the KB as Evaluation methods is constructed as at least on the graph.

We define the method as tuple $m=\left(n_{m}, t_{m}, p_{m}, b_{m}\right)$ where:

- $n_{m}$-is method name;

- $t_{m}$-is task name;

- $\quad p_{m}$-is the precondition, which is a query to KB;

- $b_{m}$-is the sequence of steps and each step is either the task or action. where:

The state transition system of the BDI agent can be described as a 4 tuple $\Sigma=(S, A, \gamma, q)$,

- $\quad S$-is a finite set of states;

- $\quad A$-is a finite set of actions. Each action has one of the states, which can belong $S$ $\in\{$ draft, executing, done, failed $\}$. There are two types of actions:

$\bigcirc \quad A_{k}$-is a set of information gathering actions. These actions do not change the world state.

$0 \quad A_{s}$-is a set of state-changing actions.

- $\gamma: S \times A_{k} \rightarrow S$-is the state-transition function. 
- $\quad q: S \times A_{k} \rightarrow Q$-is a quality function, where each $q_{i} \in Q$ is a vector.

Planning problem we define as the triple $P=\left(\Sigma, s_{0}, g\right)$ where:

- $s_{0}$-is the initial state;

- $\quad g$-is the goal.

The plan is a sequence of actions that lead to a goal state, i.e., $\pi=\left\langle a_{0}, \ldots, a_{n}\right\rangle$, and such $\gamma\left(s_{0}, \pi\right) \in S_{g}$.

All components represented in Figure 2 are required as the main components for the MC-DSS development.

\subsection{Representation of Conceptual Models for the Knowledge-Based System in the MC-DSS}

The multi-modal transportation system's technical characteristics combine important data for the evaluation procedures of transportation corridors, which were implemented in the MC-DSS. Such information contains the data about the freightage junctions, such as border crossing points (nodes of cross-boarding), main cities with different population density parameters, ports, etc.

An illustration of the description of such types of junction-nodes and relations with transportation networks is presented in Figure 3. By using the Unified Modelling Language (UML) notation, the object class diagram model is presented in Figure 3. The conceptual models are developed for constructing the required components of the KB. Some of them are stored in the data warehouses (and meta-models of repositories are stored in the KB). Such models help in the provision of context-aware services online.

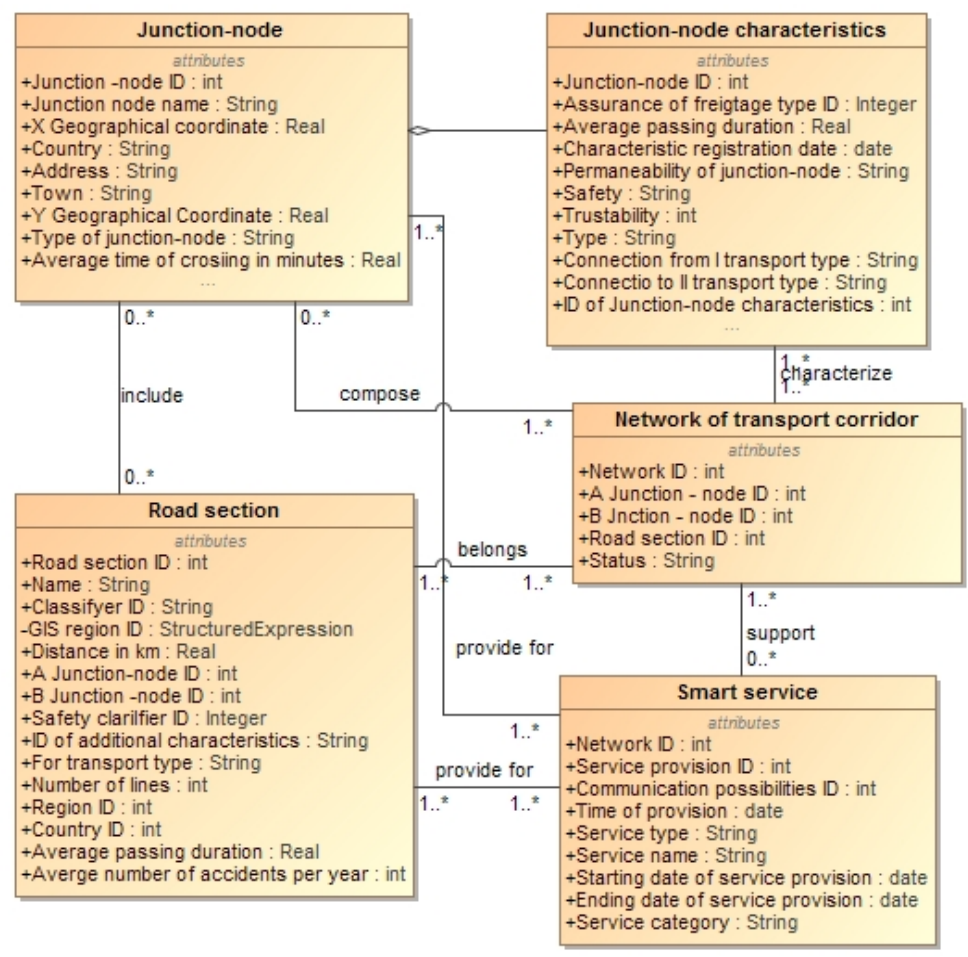

Figure 3. The part of the knowledge base for representation of highway road's network characteristics by using UML notation (i.e., object class diagram).

The system for achieving coordination of all activities during the transportation of freights have to be implemented by synchronous work of all participating actors:

- Senders;

- Forwarding agents;

- Terminal operators;

- Sea ferry bridges; 
- Ships, ferries, bridges of rivers and lakes;

- Automobile-motor transport drivers.

Some influencing components are important and can be evaluated according to the upcoming new types of autonomic transport means.

The road's technical condition should determine the road surface's technical conditions (or other characteristics) of the selected route, changing during different and specific periods in year duration. These requirements of the description of roads' technical conditions may also affect the package of requirements for transporting goods during a certain period of the year. The assessment of meteorological conditions is important in decisionmaking processes.

Some important issues arise at this stage of the system development, which we need to define as:

- $\quad$ how the requiring parameters will be entered (measured and calculated) into the system;

- how reliable sources of expertise will make the required estimations for these parameters' real determination and specific values.

The entire transport corridors, by assessing alternative routes from the same destination to the same endpoint, are described using simulation methods. The illustration of a representation of the case study's workflow model of one multi-modal transport corridor is presented in Figure 4. Such models of all analyzed transportation corridors are obtained through simulation tools realized in the system to forecast perspective and assess such alternatives.

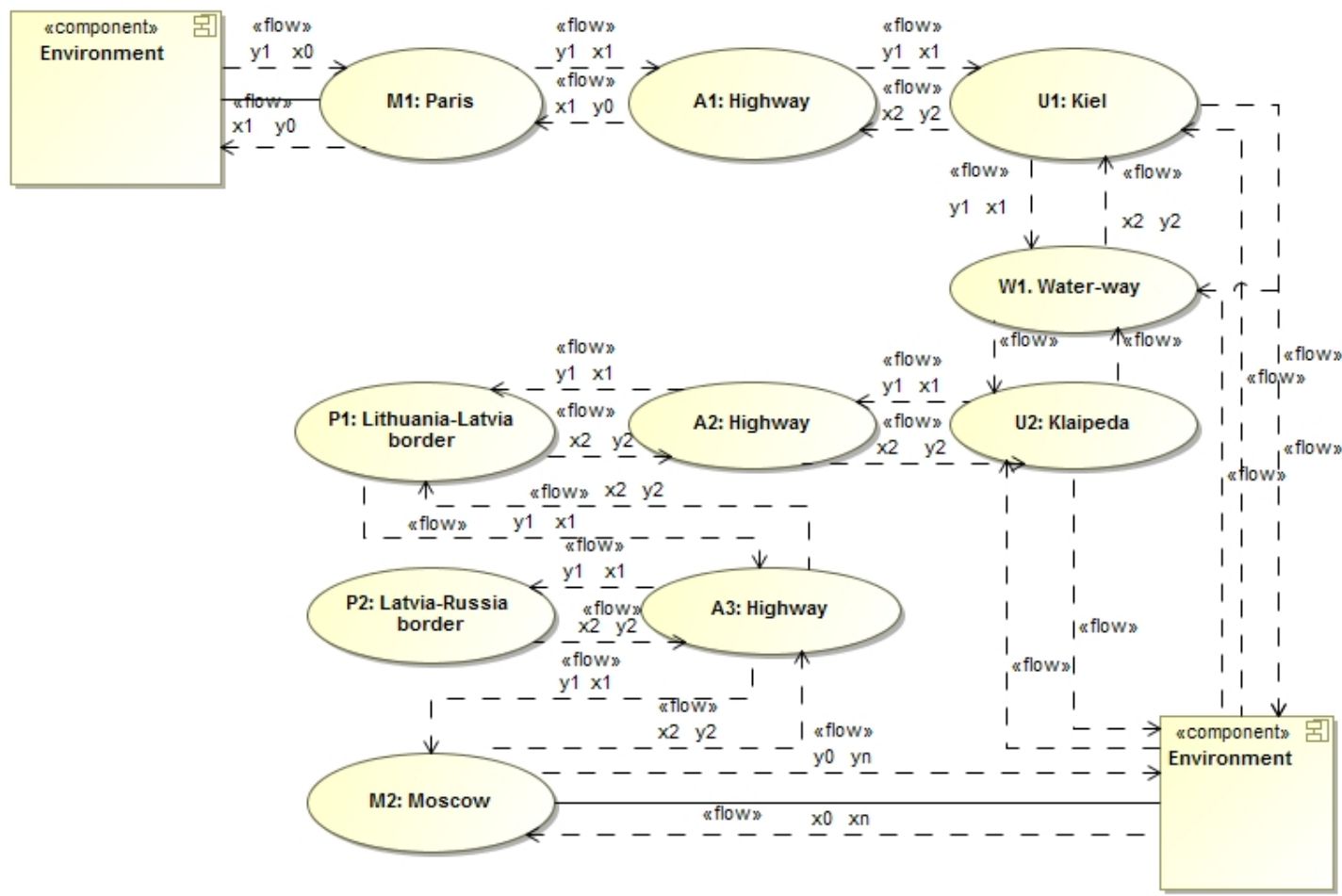

Figure 4. The illustration of a representation of the workflow model of one case of multi-modal transport corridors by using the UML notation for description of activities in the simulation model.

The specific models are created for shared networks. Non-cooperative behaviour, when users select the concrete route between origin and destination points, is influencing criteria $t r_{-}{ }_{c o s} t_{i}, \Delta t_{i}, t r_{-} r l_{i}$, in minimizing their freight transportation parameters (as costs, time duration). However, it is not possible to minimize the total cost in the network, and it is aiming at increasing the efficiency of traffics. 
It became apparent, when the conditions are changing (for example, transport mean is delaying), and the movement of traffic in urban areas are more complex to evaluate exactly. The movement of traffic includes traffic through streets and intersections. Congestions appear if traffic density is extremely high and its speed is exceptionally low-the flow reaches the maximum traffic flow. Assessment of the flow speed, which can be in situations at the minimum possible speed, can be forecasting.

The usual performing traffics analysis (naming them as standard traffic flow analysis) was started and based on the static one-period model [16]. The authors use a static oneperiod model to estimate congestion costs. It was later clarified that the static model did not capture congestion over a period. Because congestion varies, it is important to model traffic patterns within a time frame. The modelling can help to create the estimation of traffic schedules for period and location. Delivery uncertainty could also be modelled according to timeline models. Some authors are looking for possible options to reduce traffic congestion or pollution $[13,14]$.

It is necessary to state that the collected traffic flow data is used for analysis, including optimization models. Optimization models are used for controlling traffic lights, which can help to reduce traffic spikes.

4.4. The Mathematical Background of Decision Support Processes in the Finding of Adaptable and Attractive Solution from Provided Alternatives

The implementation of some types of mathematical and logical formulas, and some parts of pseudo algorithms (in this sub-section), can help in the expression of formal specification of the decision making processes in the system under development in such stage. We then need to assess the attractiveness of provided alternatives for the road corridors of multi-modal transportation. Some authors recommended the usage of the interpretation of the mined knowledge for the evaluation of analyzed entities, and the implementation of the aggregation functions are recommended to be used instead of the full simultaneity and full compensation of the evaluation objects $[48,49]$. The implementation of the weak conjunction possibility is recommended in $[48,49]$. Explaining the desired aggregation behavior as the most suitable aggregation function helps in the explanation of the multicriteria decision-making processes and for the choosing of the most suitable solution for online conditions. Some linguistically expressing possibilities are backgrounded for the application of a more adaptable solution (AS). When the calculation is based on the fuzzy sets' inappropriate constructions, the unsuitable aggregation function can be used, or summaries can be based on the analysis of outliers. Some authors implement fuzzy logic operations for such purposes.

For an illustration of the description of possible alternatives of decision-making processes under the planning stages of trips, when the evaluation of multi-modal transport corridors are, we would like to recommend the construction of the imitational model for the assessment of such transportation components and parameters (Figure 5). Diamonds represent the decision-making points in which all possible versions of solutions at specific points of the multi-modal chain corridors are assessed. Possible versions are analyzed under conditions where this can be done. 


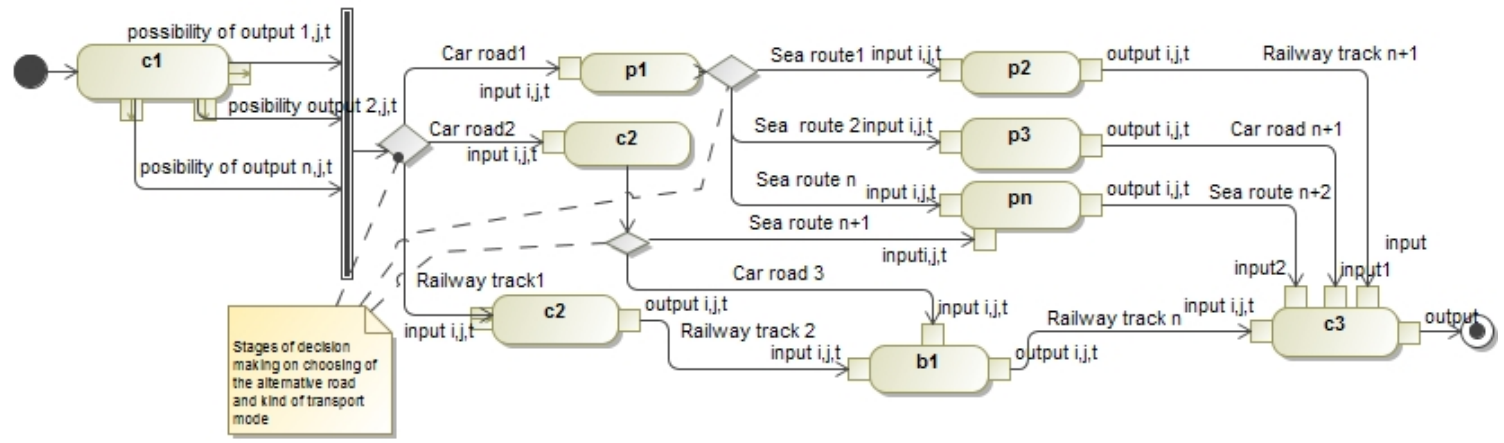

Figure 5. The illustration of the description of the decision-making process for choosing alternatives of the processes under the planning stage of trips by evaluation of different multi-modal transport corridors.

There are two sets monitoring data flow in the model, i.e., the set of outputs-Out $\left\{\right.$ output $\left.t_{i, j, t}\right\}$ and the set of inputs-Im\{imput $\left.i_{i, j}\right\}$, which are described as the out-flows and in-flows of information about the cargo (freights) appropriately; there $i=1, \ldots, n$, are identifiers of the transporting of goods; $j=1, \ldots, m$-identifiers of transport means; $t_{k}$-time moments by fixing them in the system for recording the monitoring data (and in the retrospective analysis of such data, which is extracted from monitoring data warehouses).

The monitoring data are fixed when the concrete transport mean reaches the appropriate node $n_{l}$. The recording of time moments is important for monitoring processes, and such data are stored in the data warehouses (DWs).

The monitoring DWs can help in the operative management of transportation and logistics processes and provide smart services based on the MC DSS system.

Some linguistically expressing possibilities are backgrounded for the application of a more adaptable solution (AS). When the calculation is based on the fuzzy sets' inappropriate constructions, the unsuitable aggregation function can be used, or summaries can be based on the outliers.

There are some types of nodes and activities that are marking in the simulation model of decision support processes for their recognition:

- $C=\left\{c_{i}\right\}$ is the set of cities;

- $\quad P=\left\{p_{j}\right\}$ is the set of ports;

- $B=\left\{b_{k}\right\}$ is the set of board crossing points.

The aggregating quality measures are based on the basic quality ordering relations, i.e., it is explained as having "less or equal" quality than described previous one. For the expression of the aggregating quality measures, we follow the formula described in [21] that can help to represent the evaluation process:

$$
l s_{1} \leq l s_{2} \Leftrightarrow M_{1}\left(l s_{1}\right) \leq M_{1}\left(l s_{2}\right) \wedge M_{2}\left(l s_{1}\right) \leq M_{2}\left(l s_{2}\right) \wedge \ldots \wedge M_{n}\left(l s_{1}\right) \leq M_{n}\left(l s_{2}\right)
$$

For choosing the best solution from the provided set of alternatives $\left\{l s_{k}\right\}$ of the multimodal transportation corridors, the system proceeds the piece-vice comparison of all possible measures of parameters $\left\{M_{i}\right\}$ of the alternative $l s_{k}$, with the parameters $\left\{M_{i}\right\}$ of the alternative $l_{k+1}$. Only when it is found that all parameters correspond to such conditions, the conclusion is provided - that the aggregating quality of the solution $l s_{k+1}$ is better than solution $l s_{k}$. This measure generally works when $l s_{k+1}$ is better than $l s_{k}$ by all measures. Sometimes the measures $M_{i}$ may be conflicting and partially redundant. Here, it is space for bipolarity and asymmetric conjunction. In some cases, the fuzzy logic sets are applied for the expression of intervals for overlapping parameters [50,51].

For a mathematical description of validity, coverage, and outliers, we are recommending following the results presented in $[48,49]$, which help in the assessment of the best solution of choice of one alternative, when the outliers appear in satisfying of conditions: if 
the validity degree $v$ is very small, and the sufficient coverage $C$ is very small. Generally, it is recommended to calculate such outlies by the formula, following [48]:

$$
O=t(s(v, 1-v),(1-C))
$$

$T$ is a $t$-norm, $s$ is a t-conorm, $v$ is validity, and $C$ is covered. The formula can express the coverage:

$$
i_{c}=\frac{\sum_{i=1}^{n} t\left(\mu_{S}\left(x_{i}\right), \mu_{R}\left(x_{i}\right)\right)}{n}
$$

where $i_{c}$ is the average evaluation of the founding criteria $i$ by its coverage $c$ that is influencing the forming process of concrete possible decision; $\mu_{S}\left(x_{i}\right)$ - the relative importance of the criterion $i$ that was assessed in a decision-making situation dulled by the average calculation by the relevant specialists and experts; and $\mu_{R}\left(x_{i}\right)$-the relative importance of criterion $i$ according to the structure of $R$ part importance.

The adaptable solution $(A S)$ with restriction usually covers a relatively small subset of the considered data [48], and the formula can define its coverage $C$ :

$$
C=f\left(i_{c}\right)=\left\{\begin{array}{cc}
0, & i_{c} \leq r_{1} \\
2\left(\frac{i_{c}-r_{1}}{r_{2}-r_{1}}\right)^{2}, & r_{1}>i_{c} \leq \frac{r_{1}+r_{2}}{2} \\
1-2\left(\frac{r_{2}-i_{c}}{r_{2}-r_{1}}\right)^{2}, & \frac{r_{1}+r_{2}}{2}<i_{c}<r_{2} \\
1, & i_{c} \geq r_{2}
\end{array}\right.
$$

There, adjusting $r_{1}$ and $r_{2}$ according to the structure of $R$ part.

By evaluating the quality, we can simplify that $A S$ is of high quality when validity and non-outliers of indirect coverage are high:

$$
Q_{C}=t(v, 1-O)=t(v, s((1-v, v), C))
$$

Or the coverage is defined as significant when the value of coverage is equal to or higher than 0.5 .

$$
Q_{C}= \begin{cases}t(v, C), & C \geq 0.5 \\ 0, & \text { otherwise }\end{cases}
$$

The product of $t$-norm makes this distinction, but the aggregated value is low. It is not a problem when searching for the best $A S$, but it may indicate that, even though $l_{2}$ is the best, its quality is not high.

$$
Q_{c}<(C \text { and } v) \text {, when }(C \text { and } v) \text { are lower than } 1
$$

For the mining of adaptable solution $\left(A S_{t i}\right)$ at real conditions of the situation of transportation processes, it is possible to find such an alternative by considering the linguistic description of possible solutions of interest. We can reveal all relevant summaries of the evaluating high validity. The finding of $Q, S, R$ (by [48] recommendations) on the subject could be formulated as such:

$$
\text { find } Q, S \text {, Rsubject to } Q \in \bar{Q} ; S \in \bar{S} ; R \in \bar{R} ; v(Q, S, R) \geq v_{k}
$$

$Q$ is a set of quantifiers of interest; $R$ and $S$ are sets of relevant linguistic expressions for restrictions, and can be presented by summaries or average evaluation operators of parameters, respectively; $v_{k}$ is the threshold value from the $(0,1]$ interval. It is important to state that all feasible solutions produce such linguistic summary:

$\left(Q^{*} R^{*}\right.$ are $\left.S^{*}\right)$.

For the mining of $A S_{t i}$ of interest regarding quality measures, we can reveal all relevant summaries, by considering such quality measures:

find $Q, S$, Rsubject to $Q \in \bar{Q} ; S \in \bar{S} ; R \in \bar{R} ; v(Q, S, R) \geq v_{k} c(Q, S, R) \geq c_{k} ; o(Q, S, R) \geq o_{k}$ 
where $v_{k}, c_{k}$ and $o_{k}$ are threshold value from the $(0,1]$ interval. Such equation may be converted into:

$$
\text { find } Q, S, \text { Rsubject to } Q \in \bar{Q} ; S \in \bar{S} ; R \in \bar{R} ; Q V_{c}(Q, S, R) \geq q v_{k}
$$

where $q v_{k}$ is the threshold value of the aggregated quality measure.

The set of terms of summarizing parameters can have such values $S=\{$ small, medium, high\}. The set of terms for expressing the quantifiers $Q=\{$ few, about half, most of $\}$, and such values belong more for the category of fuzzy expressions of quality.

The $A S_{t i}$ can be expressed as a relaxed conjunction, if some attributes should be satisfied, e.g., low price of the multi-modal transportation corridor:

$$
v(z)=\wedge_{j=1}^{p} \mu_{R_{j}}(z) \otimes \mu_{Q}\left(\frac{1}{q} \sum_{i=1}^{q} \mu_{P_{i}}(z)\right) \in[0,1]
$$

where $p$ is the number of hard conditions, $q$ is the number of soft conditions and $(x)$ is an aggregation by expression of conjunction or suitable of unformal conditions.

\section{Results of Analysis of Case Studies of Evaluation of Multi-Modal Transportation Corridors between East and West Regions of Europe}

The information that is retrieved covers some aspects of cargo transportation activities. One part of our empirical research study is based on the survey of specialists and experts, participating in multi-modal transportation processes, and they are asking about the rating of the set of criteria, helping into the revealing process of criteria priorities according to the evaluation of the attractiveness of alternative corridors of multi-modal transportation. The MCDM methods (described in Section 2.3) became helpful for the construction of the survey for recognizing the main evaluation criteria for our MC-DSS system, and the Delphi technique was implemented for constructing the main steps of survey provision. The Delphi technique was used by analogy, by following the recommendations of $[50,51]$. The Delphi process was implemented for the identification of patient behavior in [52] The structures of the Delphi technique were demonstrated in the work by [53] for the modelling of expert knowledge for ecological problem solution by defining the mangrove composition and estimating the time frame for recovery after the treats.

Presented in the previous Section 4 the mathematical models were used for the comparative analysis of the competitiveness of routes between Western Europe and East Europe (including Russia). Two cycles of imitational modelling were performed. The simulation model evaluates the time schedules of transport means. The criteria's significance was assessed from 1 (as the most important) to 12 (as the least important) of extracted criteria according to the carriers' specialist opinions (Table 4). The provided survey has shown that the most important criteria are cost, reliability, and transportation duration.

The intersections (nodes) of multi-modal transport are important in determining the multi-modal transport system's technical characteristics. We followed the results of works described in $[7,11,54,55]$. Each of these nodes can provide certain operational actions: delivery of a load by one type of vehicle, reloading a load to another type of vehicle, and the dispatch of a load to another junction of multi-modal transport. 
Table 4. The assessment of criteria for evaluation of one cycle trips of multi-modal transportation corridors by opinions of specialists and experts.

\begin{tabular}{|c|c|c|c|c|c|c|c|c|}
\hline \multirow{2}{*}{ No } & \multirow{2}{*}{ Name of Criteria } & \multirow{2}{*}{ Abbreviations } & \multirow{2}{*}{$\begin{array}{l}\text { Unit of } \\
\text { Measurement }\end{array}$} & \multicolumn{3}{|c|}{$\begin{array}{l}\text { Evaluation of the Importance of Criteria (from } 1 \text { until 12) by Opinions of } \\
\text { Specialists and Experts }\end{array}$} & \multirow{2}{*}{$\begin{array}{c}\begin{array}{c}\text { The Average } \\
\text { Range of Values }\end{array} \\
{\left[\mathbf{r}_{1}, \mathbf{r}_{\mathrm{we}}\right]}\end{array}$} & \multirow{2}{*}{$\begin{array}{l}\text { Choosing Weights of } \\
\text { Criteria for a } \\
\text { Simulation Model of } \\
\text { the MC-DSS }\end{array}$} \\
\hline & & & & Specialist-Expert 1 & Specialist-Expert 2 & Specialist-Expert k & & \\
\hline 1 & Transportation cost & $t r_{-} \operatorname{cost}_{i}$ & $\begin{array}{l}\text { Euros/per one trip } \\
\text { cycle }\end{array}$ & 1.0 & 2.5 & 1.5 & {$[1.3,2.5]$} & 1 \\
\hline 2 & Duration of transportation & $\Delta t_{i}$ & Duration in hours & 4.0 & 4.7 & 4.3 & {$[4.0,4.7]$} & 4 \\
\hline 3 & Transportation reliability & tr_rel ${ }_{i}$ & Quality from 1 to 5 & 2.0 & 3.0 & 2.5 & {$[2.0,3.0]$} & 2 \\
\hline 4 & Transportation security & $t r \_s e c i_{i}$ & Quality from 1 to 5 & 3.0 & 3.5 & 4.0 & {$[3.0,4.0]$} & 3 \\
\hline 6 & $\begin{array}{l}\text { Downtime at intermediate } \\
\text { customs offices and } \\
\text { trans-shipment }\end{array}$ & $\Delta t_{i, j}$ & Duration in hours & 5.0 & 4.75 & 4.8 & {$[4.75,5.0]$} & 5 \\
\hline 7 & Ensuring cargo security & tr_car_sec $i$ & Quality from 1 to 5 & 6.0 & 5.5 & 5.8 & {$[5.5,6.0]$} & 6 \\
\hline 8 & $\begin{array}{l}\text { Speed and reliability of } \\
\text { payments for transport } \\
\text { operations }\end{array}$ & $\operatorname{pay}_{\Delta i}$ & $\begin{array}{l}\text { Seconds/per } \\
\text { operation }\end{array}$ & 7.0 & 6.25 & 6.5 & {$[6.25,7.0]$} & 7 \\
\hline 10 & Quality of driver service & $d r_{-} s e r i$ & Quality from 1 to 5 & 11.0 & 10.50 & 11.0 & {$[10.50,11.0]$} & 10 \\
\hline 11 & $\begin{array}{l}\text { Professional competence of } \\
\text { freight forwarders }\end{array}$ & com_prof $f_{i}$ & Quality from 1 to 5 & 10.0 & 9.25 & 9.5 & {$[9.25,10.0]$} & 9 \\
\hline 12 & $\begin{array}{l}\text { Proficiency in foreign } \\
\text { languages of transporters } \\
\text { and service workers }\end{array}$ & Lang $_{i}$ & Quality from 1 to 5 & 12.0 & 11.25 & 11.5 & {$[11.25,12.0]$} & 12 \\
\hline
\end{tabular}


The concept of "route reliability" is a set of estimations by describing the safety characteristics of the concrete route stretch expressed as an aggregating vector of quantity. The following parameters should be considered:

- The likelihood of attacks on this route,

- $\quad$ Ensuring cargo security,

- An ecological safety factor is required, which sets restrictions on transporting environmentally hazardous goods along this route.

The created simulation model of multi-modal transportation enables us to evaluate the competitive features of the specified routes: few competitive ways can be selected for assessment from East-West and West-East directions in Europe:

1. The Baltic Sea route is the waterway through the Baltic Sea from the main European cities to one of three Baltic States (by choosing one of the ports, Klaipeda, Riga or Tallinn).

2. The land way through Belarus is the railway or highway that crosses three borders: Germany-Poland, Poland-Belarus, and Belarus-Russia, reloading the goods at Belarusian border because of different European rail track width;

3. The Finland route is the waterway through the Baltic sea from the main European cities to Helsinki, and further, it's usually the railway to Russia;

4. Through Lithuania, the land-way is a railway or highway that crosses the following borders: Germany-Poland, Poland-Lithuania, Lithuania-Belarus, and BelarusRussia, on the way to Moscow, or Germany-Poland, Poland-Lithuania, LithuaniaLatvia and Latvia-Russia when going to St. Petersburg.

5. The Klaipeda route is the waterway through the Baltic Sea from the main European cities to Klaipeda port, and further, it's usually the railway to Russia.

Some experimental cycles were carried out for evaluation of the possibilities under the conditions of improving the Baltic route's situation via the Klaipeda port. For this purpose, the prices of Klaipeda port services were reduced by $5 \%$. The percentile differences of competitive routes by evaluating such criteria are given in Tables 5 and 6.

Table 5. Percentage differences of concurrence routes by evaluating criteria (modelling cycle I).

\begin{tabular}{|c|c|c|c|c|}
\hline \multirow{2}{*}{ No } & \multirow{2}{*}{$\begin{array}{c}\text { The Name of Transport } \\
\text { Corridor-Route }\end{array}$} & \multicolumn{3}{|c|}{ Criteria } \\
\hline & & Price & Time & Reliability \\
\hline 1 & The Finland route & $100 \%$ & $\begin{array}{c}87.73 \% \\
(12.27 \%) \\
\end{array}$ & $\begin{array}{c}67.61 \% \\
(32.39 \%) \\
\end{array}$ \\
\hline 2 & The Baltic Sea route & $\begin{array}{c}72.87 \% \\
(27.13 \%)\end{array}$ & $\begin{array}{c}87 \% \\
(15 \%)\end{array}$ & $\begin{array}{c}67.61 \% \\
(32.39 \%)\end{array}$ \\
\hline 3 & $\begin{array}{l}\text { Land-way route by } \\
\text { Klaipeda }\end{array}$ & $\begin{array}{c}70.04 \% \\
(29.96 \%)\end{array}$ & $100 \%$ & $100 \%$ \\
\hline
\end{tabular}

Table 6. Percentage differences of concurrence routes after reducing the time of border crossing (results of the simulation modelling cycle II).

\begin{tabular}{|c|c|c|c|c|}
\hline \multirow{2}{*}{ No } & \multirow{2}{*}{$\begin{array}{l}\text { The Name of Transport } \\
\text { Corridor-Route }\end{array}$} & \multicolumn{3}{|c|}{ Criteria } \\
\hline & & Price & Time & Reliability \\
\hline 1 & The Finland route & $100 \%$ & $\begin{array}{c}50 \% \\
(50 \%)\end{array}$ & $\begin{array}{c}71.43 \% \\
(28.57 \%)\end{array}$ \\
\hline 2 & The Klaipeda route & $\begin{array}{c}53.33 \% \\
(46.67 \%)\end{array}$ & $\begin{array}{c}31.25 \\
(68.75 \%)\end{array}$ & $\begin{array}{c}50 \% \\
(50 \%)\end{array}$ \\
\hline 3 & $\begin{array}{c}\text { Land-way route via } \\
\text { Lithuania }\end{array}$ & $\begin{array}{c}26.67 \% \\
(73.33 \%)\end{array}$ & $\begin{array}{c}68.75 \% \\
(21.25 \%)\end{array}$ & $\begin{array}{c}64.29 \% \\
(35.71 \%)\end{array}$ \\
\hline 4 & Land-way route via Belarus & $\begin{array}{c}86.67 \% \\
(13.33 \%)\end{array}$ & $100 \%$ & $100 \%$ \\
\hline
\end{tabular}


The percentile difference is shown for description averaging characteristics, which are calculated according to some evaluation criteria. The last place was expressed by $100 \%$, where the percentile is given in practice to show how much such a competitive route is better than the worst way.

The Lithuanian multi-modal transportation market was reviewed. Several offers on improving this situation were made. This advice was provided according to the modelling characteristics, which gained in simulating a certain situation. For example, it is implemented to increase the effectiveness of work at Klaipeda port or the penetrability of border posts.

\section{Discussion}

The processes of online decision-making are related to assessing all the infrastructure components needed to support multi-modal transportation freights' managerial and control processes. The processes for today's needs are overly complex and dynamic. The results of the study were obtained by developing an evaluation methodology. Such methodology includes some layers of analysis, decision-support, and horizontal and vertical operational measures of the multi-component, multi-modal transportation freight provided for the MC-DSS development. We hope that such a system helps to provide more effective and sustainable management of such transportation processes.

The consideration of the possibilities of smart service provision is revised through the methodology of constructional possibilities of the MC-DSS. The empirical perspective is implemented and helps to choose criteria for the evaluation of transportation corridors by using specialist and expert opinions. Such system structures are under development and need to be analyzed in a more detailing style, and we are planning to perform these tasks in the future.

The complexity of the analysis of transport processes is revealed. The results are presented on more sustainable transport issues through the implementation of smart services in decision-making processes. For operational decision making, online solutions are playing a very important role.

Future works of the study will address the consideration of accident events and scenarios for helping. The possibilities of classification of the infrastructure components by other types of wireless communication channels will be performed in future, and the implementation of contextual information in the specification of constructions of smart services are under development for achieving the goal to avoid accidents and unsafe situations. Future works could also include a review of the application of smart services in the delivery of air freight transport.

\section{Conclusions}

The description of some important parts of the decision support system is presented in this paper. The main components of supporting infrastructure for providing smart services for the management of multi-modal transportation processes were described. We hope that our MC-DSS under development can help in the operative management processes of transportation.

The main structures of the MC-DSS were presented, such as constructions of the knowledge base and description of all layers of the $\mathrm{KB}$, which can integrate methods of decision making and multi-criteria evaluation. We integrated a few methods for a more real construction of KB and provided an intelligent planning tool for evaluating multimodal transportation corridors that help choose alternatives based on the real conditions of transportation.

Several options are focusing on the problems of solving sustainable transportation going forward for a more safe, cleaner, and paper-less transportation. We would like to show how we develop adaptable multi-criteria decision support methods for choosing the adaptable and attractive transportation corridor between the East and West directions of Europe. These methods are introduced in the mechanisms of working of smart services, 
which provide support for drivers under the conditions of real situations, by using artificial planning method. Two cycles of simulation models were applied, for an estimation of all required parameters for decision making, and steps of Delphi technology were implemented for the review of specialists and experts, and for extracting the importance of recognized criteria, which are important for the conditions of multi-modal transportation on land conditions.

The MC-DSS is integrated into the overall ICT of smart service provision infrastructure and is associated with communication channels between all participating parts. The types of multi-modal transportation were analyzed on the base of the underground Earth means. This approach is based on creating a service delivery infrastructure by building an operational knowledge base for operative decision support to find a more adaptable solution in real situations of freight transportation.

Author Contributions: Conceptualization, methodology, construction of the system and knowledge base-D.D.; analysis and investigation-A.B.; visualization and revision of references-A.M. All authors have read and agreed to the published version of the manuscript.

Funding: The Research Council of Lithuania (LMTLT), grant number 01.2.2-LMT-K-718-03-0030.

Institutional Review Board Statement: Not applicable.

Informed Consent Statement: Not applicable.

Data Availability Statement: Not applicable.

Acknowledgments: This research is supported by the project that received funding from the European Regional Development Fund (project No 01.2.2-LMT-K-718-03-0030) under grant agreement with the Research Council of Lithuania (LMTLT).

Conflicts of Interest: Authors declare no conflict of interest.

\section{References}

1. Colglazier, W. Sustainable development agenda: 2030. Science 2015, 349, 1048-1050. [CrossRef]

2. Verhoef, P.C.; Bijmolt, T.H.A. Marketing perspectives on digital business models: A framework and overview of the special issue. Int. J. Res. Mark. 2019, 36, 341-349. [CrossRef]

3. Osmundsen, K.; Iden, J.; Bygstad, B. Digital transformation: Drivers, success factors, and implications. In Proceedings of the Mediterranean Conference on Information Systems, Corfu, Greece, 28-30 September 2018; p. 37.

4. Sacolick, I. Driving Digital: The Leader's Guide to Business Transformation Through Technology; Amacom: New York, NY, USA, 2017.

5. Kranz, M. Building the Internet of Things: Implement New Business Models, Disrupt Competitors, Transform Your Industry; John Wiley \& Sons: Hoboken, NJ, USA, 2016.

6. Dzemydiene, D.; Maskeliunas, S.; Dzemydaite, G.; Miliauskas, A. Semi-Automatic service provision based on interaction of data warehouses for evaluation of water resources. Informatica 2016, 27, 709-722. [CrossRef]

7. Dzemydiene, D.; Burinskiene, A.; Miliauskas, A. An assessment of provision of heterogeneous services for sustainable cargo transportation process management by roads. Sustainability 2020, 12, 8405. [CrossRef]

8. Dzemydienè, D.; Dzemydaitè, G.; Gopisetti, D. Application of multicriteria decision aid for evaluation of ICT usage in business. Cent. Eur. J. Oper. Res. 2020. [CrossRef]

9. European Commission. A European Green Deal: Striving to Be the First Climate-Neutral Continent. 2019. Available online: https:/ / ec.europa.eu/info/strategy/priorities-2019-2024/european-green-deal_en (accessed on 18 March 2021).

10. European Commission. Communication from the Commission to the European Parliament, the Council, the European Economic and Social Committee and The Committee of the Regions: A European Strategy for Data. 2020. Available online: https: / / op.europa.eu/en/publication-detail/-/publication/ac9cd214-53c6-11ea-aece-01aa75ed71a1/language-en (accessed on 18 March 2021).

11. Zavadskas, E.K.; Kaklauskas, A.; Peldschus, F.; Turskis, Z. Multi-Attribute assessment of road design solutions by using the copras method. Balt. J. Road Bridge Eng. 2007, 2, 195-203.

12. Barysienè, J. A multi-criteria evaluation of container terminal technologies applying the COPRAS-G method. Transport 2012, 27, 364-372. [CrossRef]

13. Jeon, C.M.; Amekudzi, A.A.; Guensler, R.L. Evaluating plan alternatives for transportation system sustainability: Atlanta metropolitan region. Int. J. Sustain. Transp. 2010, 4, 227-247. [CrossRef]

14. Cadena, P.C.B.; Magro, J.M.V. Setting the weights of sustainability criteria for the appraisal of transport projects. Transport 2015, 30, 298-306. [CrossRef] 
15. Barić, D.; Pilko, H.; Strujić, J. An analytic hierarchy process model to evaluate road section design. Transport 2016, 31, 312-321. [CrossRef]

16. Inti, S.; Tandon, V. Application of fuzzy preference-analytic hierarchy process logic in evaluating sustainability of transportation infrastructure requiring multicriteria decision making. J. Infrastruct. Syst. 2017, 23, 04017014. [CrossRef]

17. Mitropoulos, L.K.; Prevedouros, P.D. Incorporating sustainability assessment in transportation planning: An urban transportation vehicle-based approach. Transp. Plan. Technol. 2016, 39, 439-463. [CrossRef]

18. Safaei Mohamadabadi, H.; Tichkowsky, G.; Kumar, A. Development of a multi-criteria assessment model for ranking of renewable and non-renewable transportation fuel vehicles. Energy 2009, 34, 112-125. [CrossRef]

19. Zečević, S.; Tadić, S.; Krstić, M. Intermodal transport terminal location selection using a novel hybrid mcdm model. Int. J. Uncertain. Fuzziness Knowl. Based Syst. 2017, 25, 853-876. [CrossRef]

20. Awasthi, A.; Chauhan, S.S.; Omrani, H. Application of fuzzy TOPSIS in evaluating sustainable transportation systems. Expert Syst. Appl. 2011, 38, 12270-12280. [CrossRef]

21. Castillo, H.; Pitfield, D.E. ELASTIC-A methodological framework for identifying and selecting sustainable transport indicators Transp. Res. Part Transp. Environ. 2010, 15, 179-188. [CrossRef]

22. López, E.; Monzón, A. Integration of sustainability issues in strategic transportation planning: A multi-criteria model for the assessment of transport infrastructure plans. Comput. Aided Civ. Infrastruct. Eng. 2010, 25, 440-451. [CrossRef]

23. Bojković, N.; Anić, I.; Pejčić-Tarle, S. One solution for cross-country transport-sustainability evaluation using a modified ELECTRE method. Ecol. Econ. 2010, 69, 1176-1186. [CrossRef]

24. Jones, S.; Tefe, M.; Appiah-Opoku, S. Proposed framework for sustainability screening of urban transport projects in developing countries: A case study of accra, ghana. Transp. Res. Part Policy Pract. 2013, 49, 21-34. [CrossRef]

25. Pamučar, D.; Ecer, F.; Cirovic, G.; Arlasheedi, M.A. Application of improved Best Worst Method (BWM) in real-world problems. Mathematics 2020, 8, 1342. [CrossRef]

26. Pamučar, D.S.; Savin, L.M. Multiple-criteria model for optimal off-road vehicle selection for passenger transportation: BWMCOPRAS model. Vojnoteh. Glas. 2020, 68, 28-64. [CrossRef]

27. Hashemkhani Zolfani, S.; Rezaeiniya, N.; Kazimieras Zavadskas, E.; Turskis, Z. Forest roads locating based on AHP and COPRAS-G methods: An empirical study based on iran. Economie 2011, 4, 6-20.

28. Yazdani, M.; Alidoosti, A.; Zavadskas, E.K. Risk analysis of critical infrastructures using fuzzy copras. Econ. Res. Ekon. Istraz. 2011, 24, 27-40. [CrossRef]

29. Yan, X.; Peng, Q.; Yin, Y.; Zhang, Y.; Zhong, Q. Evaluating railway operation safety situation in china based on an improved topsis method: A regional perspective. J. Adv. Transp. 2020, 2020, 1796132. [CrossRef]

30. Li, J.; Xu, X.; Yao, Z.; Lu, Y. Improving service quality with the fuzzy TOPSIS method: A case study of the Beijing Rail transit system. IEEE Access 2019, 7, 114271-114284. [CrossRef]

31. Wang, Z.; Hao, H.; Gao, F.; Zhang, Q.; Zhang, J.; Zhou, Y. Multi-Attribute decision making on reverse logistics based on DEA-TOPSIS: A study of the Shanghai end-of-life vehicles industry. J. Clean. Prod. 2019, 214, 730-737. [CrossRef]

32. Petrovic, I.; Kankaras, M. A hybridized IT2FS-DEMATEL-AHP-TOPSIS multicriteria decision making approach: Case study of selection and evaluation of criteria for determination of air traffic control radar position. Decis. Mak. Appl. Manag. Eng. 2020, 3 , 146-164. [CrossRef]

33. Deveci, M.; Canitez, F.; Gökaşar, I. WASPAS and TOPSIS based interval type-2 fuzzy MCDM method for a selection of a car sharing station. Sustain. Cities Soc. 2018, 41,777-791. [CrossRef]

34. Keshavarz-Ghorabaee, M.; Amiri, M.; Zavadskas, E.K.; Turskis, Z.; Antuchevičienè, J. Ranking of bridge design alternatives: A TOPSIS-FADR method. Balt. J. Road Bridge Eng. 2018, 13, 209-237. [CrossRef]

35. Petrović, G.S.; Madić, M.; Antucheviciene, J. An approach for robust decision making rule generation: Solving transport and logistics decision making problems. Expert Syst. Appl. 2018, 106, 263-276. [CrossRef]

36. Samanta, S.; Jana, D.K.; Panigrahi, G.; Maiti, M. Novel multi-objective, multi-item and four-dimensional transportation problem with vehicle speed in lr-type intuitionistic fuzzy environment. Neural Comput. Appl. 2020, 32, 11937-11955. [CrossRef]

37. Anton, J.M.; Grau, J.B.; Andina, D. ELECTRE and AHP MCDM methods versus CP method and the official choice applied to high-speed railway layout alternative election. WSEAS Trans. Bus. Econ. 2004, 1, 64-69.

38. Alazzawi, A.; Żak, J. MCDM/A based design of sustainable logistics corridors combined with suppliers selection. The case study of freight movement to iraq. Transp. Res. Procedia 2020, 47, 577-584. [CrossRef]

39. Pak, J.Y.; Thai, V.V.; Yeo, G.T. Fuzzy MCDM approach for evaluating intangible resources affecting port service quality. Asian J. Shipp. Logist. 2015, 31, 459-468. [CrossRef]

40. Srisawat, P.; Kronprasert, N.; Arunotayanun, K. Development of decision support system for evaluating spatial efficiency of regional transport logistics. Transp. Res. Procedia 2017, 25, 4832-4851. [CrossRef]

41. Żak, J.; Wegliński, S. The selection of the logistics center location based on MCDM/A methodology. Transp. Res. Procedia 2014, 3, 555-564. [CrossRef]

42. Iyigun, I. Evaluation of efficiency of rail transportation of black sea countries by using an integrated mcdm approach. Econ. Bus. J. 2019, 13, 305-323.

43. Rahimi-Golkhandan, A.; Garvin, M.J.; Brown, B.L. Characterizing and measuring transportation infrastructure diversity through linkages with ecological stability theory. Transp. Res. Part Policy Pract. 2019, 128, 114-130. [CrossRef] 
44. Wang, X.; Li, D.; Zhang, X.; Cao, Y. MCDM-ECP: Multi criteria decision making method for emergency communication protocol in disaster area wireless network. Appl. Sci. 2018, 8, 1165. [CrossRef]

45. Özdemir, Ü.; Altinpinar, İ.; Demirel, F.B. A MCDM approach with fuzzy AHP method for occupational accidents on board. TransNav Int. J. Mar. Navig. Saf. Sea Transp. 2018, 12, 93-98. [CrossRef]

46. Ghallab, M.; Nau, D.; Traverso, P. Automated Planning and Acting; Cambridge University Press: Cambridge, UK, 2016; ISBN 978-1139-58392-3.

47. Faccin, J.; Nunes, I. BDI-Agent Plan Selection Based on Prediction of Plan Outcomes. In Proceedings of the 2015 IEEE/WIC/ACM International Conference on Web Intelligence and Intelligent Agent Technology (WI-IAT), Singapore, 6-9 December 2015; Volume 2, pp. 166-173.

48. Wu, Z.J.; Yang, J.; Shi, P. Adaptive tracking for stochastic nonlinear systems with markovian switching. IEEE Trans. Autom. Control 2010, 55, 2135-2141. [CrossRef]

49. Liu, Y.-E.; Andersen, E.; Snider, R.; Cooper, S.; Popović, Z. Feature-Based projections for effective playtrace analysis. In Proceedings of the 6th International Conference on Foundations of Digital Games, Bordeaux, France, 29 June-1 July 2011 ; Association for Computing Machinery: New York, NY, USA, 2011; pp. 69-76.

50. Pamučar, D.; Sremac, S.; Stević, Ž.; Ćirović, G.; Tomić, D. New multi-criteria LNN WASPAS model for evaluating the work of advisors in the transport of hazardous goods. Neural Comput. Appl. 2019, 31, 5045-5068. [CrossRef]

51. Yayla, A.Y.; Oztekin, A.; Gumus, A.T.; Gunasekaran, A. A hybrid data analytic methodology for 3PL transportation provider evaluation using fuzzy multi-criteria decision making. Int. J. Prod. Res. 2015, 53, 6097-6113. [CrossRef]

52. Rao, J.K.; Anderson, L.A.; Sukumar, B.; Beauchesne, D.A.; Stein, T.; Frankel, R.M. Engaging communication experts in a delphi process to identify patient behaviors that could enhance communication in medical encounters. BMC Health Serv. Res. 2010, 10, 1-15. [CrossRef] [PubMed]

53. Mukherjee, N.; Sutherland, W.J.; Khan, N.I.; Berger, U.; Schmitz, N.; Dahdouh-Guebas, F.; Koedam, N. Using expert knowledge and modeling to define mangrove composition, functioning, and threats and estimate time frame for recovery. Ecol. Evol. 2014, 1-15. [CrossRef] [PubMed]

54. Jarašūnienè, A.; Sinkevičius, G.; Čižiūnienè, K.; Čereška, A. Adaptation of the management model of internationalization processes in the development of railway transport activities. Sustainability 2020, 12, 6248. [CrossRef]

55. Jarašūnienè, A.; Čižiūnienė, K.; Petraška, A. Research on rail and maritime transport interoperability in the area of information systems: The case of lithuania. Transport 2019, 34, 467-475. [CrossRef] 